\title{
OS KUJÀ SÃO DIFERENTES? DOENÇAS INVISÍVEIS, ALIANÇA E GUERRA NO XAMANISMO KAINGANG
}

\author{
Rogério Reus Gonçalves da Rosa
}

\begin{abstract}
RESUMO
Este artigo analisará o xamanismo kaingang, em especial as idiossincrasias, as alianças e a rivalidade dos $k u j a ̀$ curandores (xamã), para isso considerando três aspectos: os kujà têm jagrẽ (espírito auxiliar) diferentes; as doenças invisíveis dos Kaingang têm características específicas; e, por fim, os kujà rivalizam entre si para curarem seus pacientes.
\end{abstract}

Palavras-chave: Xamanismo Kaingang. Kujà. Curandor. Feitiço.

\section{ARE THE KUJÀ DIFFERENT? INVISIBLE DISEASES, ALLIANCE AND WAR IN KAINGANG SHAMANISM}

\begin{abstract}
This article will examine the kaingang shamanism, in particular idiosyncrasies, alliances and rivalry of kujà/healer (shamans), considering three aspects: kujà have different jagrẽ (auxiliary spirit); the invisible diseases kaingang have specific characteristics; and finally kujà compete each other to cure their patients.
\end{abstract}

Keywords: Kaingang Shamanism. Kujà. Healer. Sorcery.

\footnotetext{
${ }^{1}$ Etnólogo, Professor do Bacharelado em Antropologia e do Mestrado em Antropologia (PPGAnt), Coordenador do Núcleo de Etnologia Ameríndia (NETA), vinculados à Universidade Federal de Pelotas (UFPel). Este artigo está ligada à linha de pesquisa do NETA intitulada Cosmologia, Mitologia e Memória. E-mail: rosa.rogeriogoncalves@uol.com.br
} 
$\mathrm{E}$ m junho de 2005, então vinculado ao Programa de Pós-Graduação em Antropologia Social da Universidade Federal do Rio Grande do Sul, apresentei minha tese de doutorado “'Os Kujà São Diferentes': um estudo etnológico do complexo xamânico dos Kaingang da Terra Indígena Votouro"'.

A frase "Os Kujà São Diferentes" foi mencionada por meu interlocutor Jorge Kagnãg Garcia durante um diálogo sobre a formação dos kujà (xamãs) ligada ao xamanismo kaingang, fenômeno esse que envolve sábios kujà, espíritos e floresta. Em linhas gerais, o tom dessa expressão aparece em outros textos por mim publicados (ROSA, 2005; 2014), mas não foi suficientemente equacionado devido à ausência de um tópico importante: a rivalidade dos kujà/curandores em um dado território.

Assim, a partir da lógica desse xamanismo, este artigo visa compreender as alianças e, em especial, o sentimento de superação de um colega sobre outrem, considerando três aspectos: os kujà/curandores têm jagrẽ (espírito auxiliar, guia) diferentes; as "doenças invisíveis" dos Kaingang têm características específicas; e, ainda, os pacientes, seus familiares e, principalmente, os kujà/curandores estabelecem guerras uns com os outros, a partir de determinada intencionalidade.

A partir disso, retomando o contexto etnográfico que envolveu a mim e aos Kaingang do Posto Indígena Xapecó (Xapecozinho), Terra Indígena Votouro, Terra Indígena (TI) Nonoai e municípios arredores, entre os anos de 2000 e 2004, estabeleço os seguintes objetivos: de início, uma breve apresentação dos Kaingang e seu xamanismo; uma apresentação de certas doenças invisíveis que atingem 0 há (corpo) e o kuprĩg (espírito) dos Kaingang; a seguir, uma explicitação das alianças e da competição dos kujà/curandores responsáveis pelo bem-estar das pessoas; e, por fim, uma análise do envio de um feitiço (malfeito) a uma mulher por outrem, bem como o tratamento e os desafios postos a esse coletivo a partir desse momento.

\section{OS KAINGANG E SUA PRÁTICA XAMÂNICA}

Os Kaingang, vocábulo que nomeia "gente do mato", são parte das Sociedades Jê, ligados ao tronco linguistico Macro-Jê. Eles estão entre os quatro povos ameríndios mais populosos do Brasil, atualmente com trinta e sete mil pessoas. A maioria dos Kaingang está concentrada em terras indígenas

\footnotetext{
${ }^{2}$ Trabalho construído sob a orientação da Prof ${ }^{\mathrm{a}}$. Dr ${ }^{\mathrm{a}}$. Cornelia Eckert e co-orientação do Prof. Dr. Robert R. Crépeau (Université de Montréal).
} 
reconhecidas pela Fundação Nacional do Índio (FUNAI) nos estados de São Paulo, Paraná, Santa Catarina e Rio Grande do Sul, além de acampamentos e aldeias situados na periferia das cidades, rodovias e unidades de conservação.

Com relação à economia, os Kaingang são caçadores, coletores, produtores de artesanato, trabalhando também como bóias-frias (diaristas) nas propriedades de alemães, italianos, poloneses e brasileiros durante a colheita da soja, do milho, da maçã e do feijão.

Tratando-se do sistema dualista, os Kaingang se dividem nas metades denominadas kamẽ e kanhru. Para os velhos kaingang do Xapecozinho, a metade kamẽ é considerada "mais forte" na relação com os espíritos, sendo constituída pelas subdivisões kamẽ e wonhetky e a metade kanhru, tida como "mais fraca", formada pelas subdivisões kanhru e votor. Essas metades são homônimas aos heróis mitológicos que pereceram nas águas diluviais, sendo que as mesmas são concebidas como exogâmicas, patrilineares, complementares e assimétricas (BORBA, 1908, CRÉPEAU, 1994).

Com relação ao xamanismo, nas últimas décadas a etnologia destaca que, entre os Kaingang, o kujà é o xamã desse coletivo, sendo o mesmo traduzido para o português como "curandor" e até mesmo "pajé" (palavra de origem tupiguarani).

Esse profissional da saúde tem como seu parceiro uma diversidade de jagrẽ (espíritos auxiliares) que assumem tanto a forma não-humana como a humana: o espírito animal da floresta (por exemplo, jaguatirica, gavião, coruja e cachorro), o espírito vegetal da floresta (taquara, árvore e cacique das matas), a água (espírito água da floresta e água santa) e o santo do panteão do catolicismo popular (Nossa Senhora Aparecida, Santo Antônio e São João Maria).

A possibilidade de um kujà trabalhar com o jaguar e a Nossa Senhora Aparecida revela que essa instituição social está atravessada por dois sistemas ideológicos sobrepostos, que constituem uma unidade: o "sistema kujă" e o "sistema caboclo", respectivamente.

A partir da lógica do saber guiado, no sistema kujà a ênfase do xamanismo está colocada no trabalho de mediação do kujà a partir do domínio "floresta virgem" vinculado ao poder do jagrẽ animal ou vegetal, à língua kaingang e ao prestígio da floresta enquanto instituição. Por sua vez, no sistema caboclo, o destaque está no trabalho do curandor kaingang ou caboclo (brasileiro) a partir do domínio "casa" e "espaço limpo", vinculados ao poder dos santos ligados ao 
panteão do catolicismo popular, à língua portuguesa e à influência das instituições altarzinho ${ }^{3}$ e igrejinha de tabuinhas . $^{4}$

Saliento que o complexo xamânico kaingang não separa o sistema kujà e 0 sistema caboclo. Sobrepondo a floresta pela casa ou pelo espaço limpo, o espírito da jaguatirica pelo santo do panteão do catolicismo popular, traduzindo kujà por curandor, o sistema caboclo replica a lógica do sistema kujà marcado pela diversidade de espíritos/santos e, particularmente, pela unidade da floresta/deus (ROSA, 2014).

Tratando-se da relação kujà e jagrẽ e das metades kamẽ e kanhru, o contexto etnográfico define a qualidade dessa ligação. Ou seja, tanto o jagrẽ poderá ter a sua "marca" associada à mesma metade do kujà (CRÉPEAU, 2007) quanto ser da metade oposta (ROSA, 2011; 2014).

Além disso, essa relação é marcada por um vínculo matrimonial. Esse casamento ocorre na floresta virgem quando o parceiro espiritual introduz no corpo do kujà, sobre cada axila ou em seu peito, sementes de nome kaáfei que confirmam o vínculo conjugal entre os dois (CRÉPEAU, 1997). Tratando-se ainda desse casamento mítico, a relação do/a kujà com sua/seu jagrẽ é marcada por ciúmes e disputas com o/a cônjuge humano/a desse xamã. Uma kujà explica que há dois tipos de jagrẽ: aqueles que consentem a união carnal dos kujà com um/a parceiro humano e aqueles que não aprovam esse tipo de compromisso. Esse segundo jagrẽ é chamado de "guia de ferro" (ROSA, 2011).

Outra condição básica desse xamanismo é o kujà/curandor trabalhar associado a seu jagrẽ, acessando o conhecimento dele através de sonhos noturnos tanto na floresta quanto em casa. Embora a experiência onírica seja valorizada por todos os Kaingang, o kujà é o único que tem acesso a tais visões e diálogos na língua kaingang por livre escolha. Em outras palavras, através do sonho, o trabalho do kujà recebe uma forte influência do jagrẽ, por exemplo, na seleção de remédios do mato às pessoas vitimadas por algum feitiço (ROSA, 2011).

0 poder de um kujà advém do seu jagrẽ da floresta ou do panteão do catolicismo popular. Como extensão disso, a antecipação de um xamã frente a um

\footnotetext{
${ }^{3} 0$ altarzinho é um espaço onde são colocadas as imagens dos santos católicos que trabalham para um kujà/curandor. Ele está localizado em uma fronteira do domínio casa, geralmente o cômodo que se dorme (ROSA, 2005).

${ }^{4} \mathrm{~A}$ igrejinha de tabuinhas é uma instituição localizada no domínio casa ou espaço limpo; consiste em uma peça única de madeira lascada, retangular, piso de chão batido, com uma única porta na frente voltada à leste e janelas nos dois lados e coberta com telhas (ROSA, 2005).
} 
infortúnio individual ou coletivo revela a capacidade de seu poder, quer dizer, o domínio que esse profissional tem das relações espirituais, sendo que somente ele pode controlar tal potência para os humanos.

o kujà é um especialista que não costuma comentar com as demais pessoas o seu dom particular. Os Kaingang costumam usar a palavra "segredo" da língua portuguesa para explicar ao pesquisador a situação de o kujà não falar a respeito da sua relação particular com os espíritos ou com o mundo dos mortos. Os mesmos revelam que o trabalho de um kujà é árduo; quanto mais pessoas sabem, mais ele se afadiga.

Tratando-se do Votouro, os seguintes kujà/curandor trabalharam/trabalham pelo bem-estar desse coletivo: [falecidos] Kaingang Maria Forte (viveu na TI Nonoai e Votouro; metade kanbru; espírito auxiliar: dois cachorros e São João Maria); Kaingang Cristina Kỹnója (TI Votouro; kanbru; São João Maria); Kaingang Guilherme Pinto (kanbru); Kaingang Maria de Paula (TI Ventarra; kanhru; glug/gato do mato, Deus, Jesus, Nossa Senhora Aparecida e Nossa Senhora da Luz); Kaingang Matilde da Silva (TI Votouro; kamẽ; São José); João Lopes (cidade Nonoai; Nossa Senhora Aparecida, São Pedro, São Jorge e São João Maria); [contemporâneos] Kaingang Luisa Jagnigri Pedroso, também chamada de Luisa Marcolina (TI Nonoai e TI Votouro; kamẽ; tigre); Kaingang Madalena de Paula (TI Votouro e Kỹnója; kamẽ; três bichinhos, gato do mato, Santo Antônio e São João); Kaingang Domingos Catabilio (TI Votouro; kanhru; pomba); Darci Brandino (TI Votouro); Kaingang Jorge Kagnãg Garcia (TI Votouro e TI Nonoai; kamẽ; tigre/jaguar); Carolina Pereira da Silva/Carula (cidade Nonoai; Nossa Senhora Aparecida, Santo Antônio, São Bom Jesus e São João Maria); Joane Xavier Rigon (cidade Faxinalzinho; Nossa Senhora Aparecida, São João Maria e Santo Antônio); Sofia Kischer (cidade Faxinalzinho; Nossa Senhora Aparecida, Santo Expedito, Santa Clara e Nossa Senhora Santa Cruz); Teresa Peskagar (Barra Seca, na divisa do Votouro); e, Cecília (cidade Erechim) (ROSA, 2005).

Aliás, embora os kujà trabalhem com diversos tipos de doenças provocadas pelos espíritos, no Votouro eles assumem determinadas especializações. Assim, seu Domingos Catabilio se considera um "ginecologista", um especialista de doenças de mulheres. Já Luisa Marcolina e Madalena de Paula são as "pediatras", conhecedoras das crianças. Por sua vez, Sofia Kischer é hábil para tratar 0 "amarelão" e a "anemia". 
Como no caso dos Goajiro, que vivem entre a Venezuela e a Colômbia e diferenciam as doenças de tipo ayuulee e wanülü̈̈5 (PERRIN, 1978), os Kaingang também possuem uma concepção específica de suas kaga (doenças), noção essa que transcende 0 aspecto meramente físico da enfermidade (HAVERROTH, 1997).

Segundo Moacir Haverroth, tratando-se dos Kaingang, o diagnóstico, 0 acompanhamento do quadro clínico e a cura da pessoa doente envolvem a participação do paciente, dos familiares diretos e do kujà. Com relação ao trajeto terapêutico, a primeira avaliação da doença é realizada pelo próprio doente e/ou por seus parentes mais próximos e/ou algum vizinho, a partir dos sintomas imediatos da moléstia. A persistência da indisposição e 0 agravamento do sofrimento físico da pessoa implicam a reclassificação do mal-estar, um novo diagnóstico e a busca da sua causa. A partir desse momento, então, segundo Haverroth, "a busca de um especialista é necessária, podendo ser um xamã, quando o principal objetivo é com a causa da doença, mais que com os sintomas." (HAVERROTH, 1997, p. 72).

De forma geral, com relação às técnicas de êxtase, os kujà/curandores que atendem aos Kaingang empregam de forma conjunta ou separada o trabalho de espíritos auxiliares, além de sonhos, novenas em altarzinhos e igrejinha de tabuinhas, procissões e, principalmente, remédios do mato composto por folhas, cascas, raízes, sementes, tubérculos, resinas, flores, frutos, brotos e cinzas de madeira $^{6}$ (OLIVEIRA, 1996; ROSA, 2005).

0 remédio do mato que o kujà coleta na floresta é uma planta que nasce sozinha na mata fechada, protegida dos raios de sol, da intervenção direta do olhar e da mão humana. Devido a esses aspectos, os kujà têm restrições ao uso de ervas coletadas em beira de estradas, à vista das pessoas e expostas aos raios do sol (ALMEIDA, 2004; OLIVEIRA, 1996; 2000).

A coleta das plantas na floresta é uma atividade individual do kujà/curandor. Eventualmente, dependendo da hora que ele se dirige à mata e da quantidade de ervas a buscar, ele pode demandar o auxilio de alguém da sua rede de parentesco ou uma pessoa de sua estrita confiança.

A preparação desse remédio a partir de uma ou mais plantas depende do tipo de doença, da forma de tratamento proposto pelo kujà, do resultado desse

\footnotetext{
${ }^{5}$ Entre os Goajiro, enquanto a doença de tipo ayuulee não demanda a presença de um xamã a doença de tipo wanülü̈̈ requer a presença de um especialista (PERRIN, 1978).

${ }^{6}$ Conforme percebeu Haverroth (1997), entre os Kaingang do P.I. Xapecó, todas as plantas são remédio do mato, sendo que podem ser usadas de forma isolada ou casadas com outras espécies.
} 
processo no paciente e do sistema de metades. Conforme pesquisa realizada por Haverroth (1997, p. 88), "há alguns remédios que são conhecidos para serem utilizados por pessoas kamẽ, outros por pessoas kanbru." "

Coletado na floresta, o remédio do mato é cozido e preparado na casa do responsável pela cura - e consumido exclusivamente pela pessoa enferma. Por sua vez, a responsabilidade pelo deslocamento desse remédio da casa do kujà/curandor à residência onde se encontra a pessoa enferma compete aos familiares dessa ou ao próprio doente.

De fato, as exceções a essa lógica ficam por conta das situações em que 0 enfermo está fisicamente impossibilitado de se deslocar até a casa do profissional, como no caso de alguém estar muito fraco, ou quando ele necessita intervir em um feitiço alojado na casa da vítima, situação essa que exige uma reparação espiritual ou a mudança dessa pessoa para outro espaço. Mas, mesmo nesses casos, as visitas desse profissional da saúde são bastante pontuais; ou seja, eles se deslocam, tratam a pessoa enferma e retornam logo após às suas moradias.

Na verdade, isso também está relacionado à sua idade. Os kujà/curandor que atendem os Kaingang quando mais jovens prestam auxílio às pessoas tanto nos seus altarzinhos quanto nos domicílios de seus pacientes. Assim, grandes deslocamentos, noites em claro e temperaturas extremas não são obstáculos ao tratamento. Porém, à medida que a idade avança e o seu prestígio se consolida junto ao (seu) coletivo e nos municípios vizinhos, esses profissionais diminuem 0 ritmo de suas viagens e passam a priorizar o atendimento em sua própria casa. Mas, em caso de extrema gravidade é uma obrigação do kujà se deslocar ao local do paciente.

A enfermidade de uma pessoa esta relacionada à ruptura temporária do bá (corpo) de seu kuprĩg (espírito), separação esta motivada pelo rapto do kuprĩg por algum espírito da natureza, por um vẽnh-kuprĩg-kòrèg (espíritos dos mortos) de um parente falecido, por um feitiço motivado por uma relação de ciúmes entre a pessoa doente e um potencial inimigo. Enfim, para se avançar nessa discussão coloca-se agora a necessidade de um novo tópico.

\footnotetext{
${ }^{7}$ Para Haverroth, o critério mais usado pelos Kaingang para a definição do sistema de metades das plantas é a cor e o formato das mesmas. Isto é, enquanto as plantas brancas e compridas (tèj) são kamẽ, as plantas escuras, pretas e redondas (ror) são kanhru (HAVERROTH, 1997).
} 


\section{AS DOENÇAS QUE ATORMENTAM OS KAINGANG}

Como no caso dos Siona que vivem no rio Putumayo, na Amazônia colombiana, pesquisados por Jean Langdon, os Kaingang diferenciam as doenças provocadas pelo rapto de seus kuprĩg pelos vẽnh-kuprĩg-korég que vivem no nũgme (mundo dos mortos) daquelas provocadas por um feitiço enviado à casa da pessoa vitimada (LANGDON; BAER, 1992; ROSA, 2005).

Tratando-se do acompanhamento da evolução do quadro clínico, no ataque de espíritos, através da técnica de êxtase do sonho, o kujà se desloca à floresta, segue através de uma estrada escura em direção ao nũgme, nesse domínio ele procura convencer o kuprĩg da pessoa raptada a retornar com ele para a casa. Nas palavras de Ledson Kurtz de Almeida (2004, p. 178):

Na concepção Kaingang cada pessoa possui três almas: kumbã, kunvê e kuprim [kuprĩg]. Kunvê é uma sombra, quase apenas como um reflexo. Está presa ao corpo porque é surda, se confunde com a própria noção de corpo. Kumbã e kuprim se confundem, mas estão atribuídos respectivamente à alma e espírito. Com a fala a pessoa passa a adquirir pecado. A fala também está relacionada com a presença de kumbã e kuprim no corpo, visto que um dos sinais de abandono deles é a própria perda da fala. Contudo, na concepção geral, a pessoa nasce com o corpo, a alma e o espírito, sendo o espírito fundamento de todos (grifos do autor).

Já com relação ao feitiço, o kujà devolve ao remetente 0 malfeito, a doença invisível que atormenta a vida de seu paciente. Nas duas situações, a demora tanto por parte dos familiares do doente na busca do serviço de um kujà, quanto desse mediador em partir ao nũgme ou cozer remédio do mato pode acarretar a morte do enfermo. Veja, a seguir, alguns tipos de doenças invisíveis mencionados pelos Kaingang.

\section{AS DOENÇAS INVISÍVEIS}

A debilidade que demanda maior preocupação por parte dos Kaingang do Votouro é a doença invisível. Trata-se de um tipo de enfermidade cujas causas principais são 0 ataque de espírito e 0 feitiço. 
No primeiro caso, o kuprĩg da pessoa vitimada pode ser raptado por um espírito do mato ou por um vẽnh-kuprĩg-korég nos domínios casa, espaço limpo e floresta virgem. Nessa situação, o espírito dessa pessoa é aprisionado no nũgme (mundo dos mortos), situado embaixo da terra, a oeste da aldeia. Ou seja, para os kujà/curadores kaingang, as pessoas sempre estão sujeitas às influências de outros espíritos: de vivos (kuprĩg) e mortos (vẽnh-kuprĩg-kòrèg).

No segundo caso, o corpo da vítima entra em contato com alguma substância enfeitiçada, oriundo de um potencial inimigo, enviada através do vento à pessoa identificada para ser afetada, podendo também ser colocada próximo a um objeto em sua casa. Devido a isso, os Kaingang muitas vezes têm o hábito de construir residências com duas aberturas (portas) para a passagem do ar nesse domínio.

De forma geral, a confirmação da doença invisível acontece a partir da quebra das regras sociais, do desvio do comportamento social, de atitudes inesperadas por parte da pessoa vitimada. Já a confirmação do feitiço dá-se a partir do momento em que a pessoa cai adoecida na cama, em que persiste a sua indisposição e sofrimento físico após as primeiras tentativas de cura por parte de um familiar ou vizinho e após o malogro com relação ao atendimento da medicina oficial. Nesse caso específico, quando um kujà é chamado, ele realiza a técnica de extração de objetos do corpo da vítima, como pequenos gravetos, lascas de taquara, cabelos ou ossos de galinha, tudo isso na frente dos familiares da mesma. Segundo Luisa Marcolina: "Votouro tem gente medonha ali, ali tem um rapaz que chegou a vomitar taquara, graça a Deus, foi curado".

De fato, um Kaingang afirmou que o setor Campina é o espaço mais perigoso para alguém morar devido à feitiçaria. Conforme suas palavras: "tenho medo de passear lá, eu tenho os meus amigos lá; mas cada domingo, sábado, eles vêm passear aqui. Eu tenho medo. A gente fraca já pega”. Como se verá logo a seguir, o malfeito não escolhe nem setor, nem redes de parentesco, pois se trata de uma prática que se apresenta em todas as terras indígenas e arredores.

Desse modo, algumas situações que foram relatadas sobre doenças invisíveis provocadas devido a ataques de espíritos são as seguintes: 1) ataque do espírito da taquara nas crianças que passam pela floresta; 2) ataque dos espíritos dos mortos do nũgme devido à saudade de um parente que permanece na terra; 3) ataque de um espírito de Kaingang vivo a um parente por vingança. Já tratandose do envio de feitiço por alguém: 4) desejo por um bem econômico; 5) desejo sexual pelo/a cônjuge; 6) disputa por emprego; 7) sucessão no cacicado; 8) revide de um pastor de uma igreja pentecostal ao trabalho do kujà (e vice-versa) devido à 
disputa por um Kaingang que oscila entre os crentes e os católicos; e, 9) revide de um malfeito por um kujà, em represália à pessoa que vitimou o seu paciente.

A seguir, apresento certos episódios narrados pelos Kaingang que ilustram alguns tipos de doenças invisíveis mencionados acima.

\section{POR QUE OS ESPÍRITOS DA FLORESTA ATACAM AS CRIANÇAS KAINGANG?}

A floresta é um espaço povoado de seres e espíritos visíveis e invisíveis. Desse modo, caçadores, meladores, pescadores, guerreiros e kujà são minoria nesse território habitado também por káká (gavião), mĩg (tigre), jagrẽ, vẽnhkuprĩg-kòrèg, vento, água, árvores, minerais, entre outros seres.

Em uma conversa com Lucídia Pinto, no Votouro, essa Kaingang comentou que todos os seres animais, vegetais e minerais, visíveis e invisíveis, possuem tóg (lê-se "tar"), quer dizer, eles têm força. Em suas palavras, "o ouro tem tóg, eu tenho tóg, a água, o mato, a noite, o sol, a lua têm tóg". Devido a isso, todos os seres vivem em movimento, deslocando-se, tornando-se visíveis e invisíveis diante do olhar de um kujà/curandor das pessoas.

Para domesticar o tóg de um animal, vegetal e mineral que alguém cruza, os Kaingang devem pingar três gotas de sangue sobre o mesmo. Diga-se de passagem, esse conhecimento pertence a todos os Kaingang, pois ele aparece desde a narrativa do kujà Jorge Kagnãg Garcia a respeito de seu primeiro encontro com o jagrẽ jaguar na floresta (ROSA, 2005, 2014) até a recomendação que fez Lucídia Pinto ao seu falecido marido, no dia em que o mesmo encontrou ouro na sua roça: "0 italiano [marido de Lucídia] achou uma pedra de ouro que dentro trocava a cor. Ele disse, 'que bonita esta pedra!'. Colocou-a em cima do toco; depois, nem sinal, porque ele não batizou."

Da mesma forma que as pessoas, os espíritos dos animais, vegetais, minerais e espaciais relacionam-se entre si e com os demais - incluindo-se os humanos - orientados por determinadas disposições. Isto é, eles também sentem mais ou menos atração um pelo outro e, inclusive, para com seus vizinhos kaingang, essas pessoas que transitam pelas mesmas fronteiras em que os espíritos residem.

Dessa forma, quando Luisa Marcolina e seu jagrẽ tigre iam ao "matão" para buscar remédio do mato, outros espíritos apareciam para conversar com eles, inclusive permanecendo próximos durante esse diálogo. Essa kujà também 
comentou que esses espíritos não ficavam parados no chão como fazem os humanos, mas, sim, "falando no ar". Foi a partir dessas trocas com esses seres que Luisa veio saber que todos os espíritos da floresta simpatizam com o espírito da água - por outro lado, que essa tendência não se repete quando se trata do espírito da taquara.

0 motivo da discórdia é que o espírito da taquara aprecia prender o kuprĩg das crianças kaingang quando as mães vão à floresta coletar cipós para fabricar artesanato. Apesar de todos os espíritos que ali residem terem propensão a esse tipo de rapto, o espírito da taquara é o mais afoito nessa prática com as crianças indefesas. Segundo Luisa Jagnigri: "por isso as mães colocam as crianças nas costas, amarradas com um pano, de medo dos espíritos da taquara assegurarem 0 espírito das crianças".

\section{RElato DE UM ATAQUE DE ESPÍRITO POR VINGANÇA DISSIMULADO POR UMA KUJÀ}

Durante $o$ trabalho de campo realizado entre os Kaingang do Votouro, uma vez escutei o relato do espírito de uma pessoa prestes a falecer que desejou raptar outrem, interceptado a tempo pela kujà Madalena de Paula:

Se a pessb́a não tá bom porque o espírito está perdido. Às vezes um parente leva um espírito do parente, daí eu tenho que ir atrás, trazer aquela pessoa. Que nem esses dias, o espírito do falecido Leopoldo [Farias], antes dele morrer, um mês antes que ele ia morrer, eu tava ali sentada na escada, lavando meus pés na boca da noite, quando eu vi aquele vulto branco assim, vinha vindo, desconfiei: 'mas escuta, isso aí não é gente!'. Daí me levantei, fui encontrar ele lá, bem ali, mas já conheci ele, de prosa já conheci ele, daí ele disse:

- Parente?!

- 0 quê?

- Tô campeando [procurando] uma sobrinha minha.

- Mas de que jeito?

- Não, ela tá me devendo. Ela tá me devendo. Eu não sei se ela vai me pagar o que ela está me devendo.

Mas dito e certo. Até agora não rebocaram o túmulo que eles fizeram pra ele. 
- 'Eu não sei se vou receber mais'. Ele disse pra mim.

- Daí eu disse: 'Deixa então que daí eu vou cobrar'. Eu falei assim pra ele. 'Mas daqui tu tem que voltar, daqui pra frente não tem estrada, tu tem que voltar daqui mesmo'.

- Ele disse: 'Sim, filha, vou voltar, vou voltar, filha, mas só que me pede isso aí, elas estão me devendo e pra mim não vão pagar.

- 'Deixa que eu vou mandar eles pagar.'

Até agora não rebocaram o túmulo dele ainda. Dito e certo o que ele me falou, que eles não iam mais pagar pra ele.

A narrativa de Madalena de Paula destaca o sentimento de cólera do espírito de Leopoldo Farias em relação a uma sobrinha poucos dias antes do falecimento dessa pessoa.

A seguir, trago uma nova situação, a mais grave de todas, sobre a presença da doença invisível entre os Kaingang, sendo que dessa vez nenhum $k u j a ̀$ curandor conseguiu se antecipar a tal evento. Isso porque, quando as pessoas perceberam o que se passava com Gãr Fej, ela já estava quase, segundo sua própria definição, "adubando a terra".

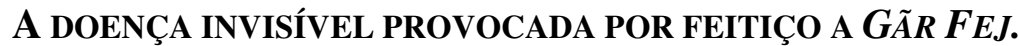

Sem dúvida, tratando-se da saúde de uma pessoa, a situação mais comentada pelos Kaingang durante a realização do trabalho de campo na TI Votouro foi o feitiço enviado à casa de Gãr Fej.

No mês de fevereiro de 2003, eu estava sentado ao lado do fogão a lenha na casa de Vẽnh $V \tilde{l}$, bebendo chimarrão, conversando com essa pessoa sobre a sua infância, quando escutamos um forte "bom dia" vindo da porta — tratava-se da Kaingang de nome Gãr Fej.

- Vẽnh Vĩ: Veio a pé?

- Gãr Fej: Ahã! Dessa vez não arrumei carona.

- Vẽnh Vĩ: Criou coragem! Essa aqui é a mulher que estava desenganada. A tal da falecida!

- Autor: Teve doente? 
- Gãr Fej: Deus o livre, taí o Vẽnh Vĩ pra contar. Hoje levantei cedo, fui buscar lenha: - 'pai, eu vou junto'. - 'será que tu aguenta?' - 'vou tentar. Cheguei com ele'.

Gãr Fej tinha, naqueles dias, trinta e seis anos de vida. Ela era casada com Kajẽr com quem tem quatro filhos. Conforme narrativa de Gãr Fej, ela estava em sua casa, acompanhada de sua sogra, trançando artesanato para revender na cidade. De repente, a sua pressão começou a cair e ela se sentiu fraca. Nesse momento a sogra lhe recomendou que fosse deitar um pouco, conselho que Gãr Fej seguiu após não conseguir finalizar o último balaio: "tia, não tô nada boa, meu corpo começou a me repuxar tudo".

Preocupados com o estado de saúde de Gãr Fej, os pais a levaram ao posto de saúde. A auxiliar de enfermagem da comunidade verificou a pressão e receitoulhe um calmante. Todavia, Gãr Fej chegou em casa sentindo-se pior: "o meu rapaizinho disse pro meu pai: 'vou buscar o carro lá porque ela não esta nada boa'”.

Nesse momento chovia no Votouro e as estradas de chão batido estavam enlameadas. Quando Gãr Fej chegou com seu filho ao Hospital de Caridade da cidade de Nonoai, ela não conseguia mais caminhar sozinha. Dessa vez um médico examinou Gãr Fej e também não diagnosticou nada, resignando-se a comentar que ela estava com pressão baixa e que logo iria melhorar. No dia seguinte, ela acordou sozinha no quarto do hospital, sentindo-se pior, com fortes tonturas. Apesar disso, o médico deu alta a Gãr Fej e, logo depois, ela estava em casa novamente acamada e a família ainda mais preocupada.

Gãr Fej narrou-me durante o encontro na casa de Vẽnh Vĩ que havia ficado com a barriga inchada, que não sentia mais fome, passando cinco dias e meio sem comer e beber nada. Durante esse período, ela perdeu a fala, passando 0 tempo todo deitada na cama, somente olhando e escutando as pessoas ao seu redor. Durante as madrugadas, Gãr Fej ficava com a garganta seca e, por esse motivo, os familiares deixavam um caneco com água potável reservado ao lado de sua cama. Segundo ela, "tava vendo que estava indo sem chegar a minha hora".

Após ter escutado esse relato, os pormenores desse mal-estar de Gãr Fej, a ida ao posto e ao Hospital de Caridade, o retorno para casa, a não resolução da enfermidade, eu perguntei, afinal, que doença ela tinha. Gãr Fej e Vẽnh Vĩ riram juntos. Logo em seguida comentou Gãr Fej: "só Deus pra saber!"; 0 curandor Vẽnh Vĩ complementou dizendo, "sabe que existe doença invisível?". 
Desse momento em diante, os dois mudaram de assunto, falaram da visita do novo padre à cidade de Faxinalzinho, depois Vẽnh Vĩ deu início à novena. Nesse dia, eu saí dessa casa pensando que, finalmente, conhecera a Kaingang que havia sido enfeitiçada por outrem. Mas, quem seria a pessoa que teria enviado 0 feitiço a Gãr Fej, qual a razão disso, quem mais participou dessa cura?

Antes de analisar mais detidamente o envio do feitiço a Gãr Fej em sua casa e as tensões que se desdobraram a partir disso entre os kujà/curandor do Votouro e vizinhança, apresentarei alguns dados relativos às alianças e às rivalidades desses profissionais do bem-estar kaingang.

\section{ALIANÇAS E GUERRAS DOS KUJÀ/CURANDORES}

Os $k u j a ̀$ /curandores são pessoas de personalidade forte, além de serem algumas vezes ranzinzas, geniosas e idiossincráticas. Para ilustrar isso, tratando-se da iniciação de Joane Xavier Rigon, esse homem me disse que o curandor responsável por sua formação comentou que ele tornar-se-ia 0 "maior curandeiro do mundo". Assim, durante nosso convívio, Joane freqüentemente usava a expressão "o maior curandeiro do mundo" como uma autodefinição, para marcar a sua identidade e a sua autoridade frente aos demais kujà/curandores da região.

Ou seja, cada um deles tem uma elevada autoestima, percebe-se mais capacitado para curar as pessoas enfermas que outrem, muitas vez, um oponente direto em busca do atendimento e do reconhecimento da mesma clientela.

Enfim, a guerra de kujà/curandores é outra característica dessa prática xamânica e parte disso acontece devido às diferenças em torno das espécies dos espíritos auxiliares e a qualidade do poder transmitida por esses aos kujà. Segundo Jorge Kagnãg Garcia:

Os kujà sempre duvidaram um do outro por causa que eles não são todos iguais; um tem um jagrẽ que domina, tem gavião, tigre, gato, 0 cacique deles; então, de certo o animal tem contato, foi tudo Deus que deixou.

Com poucas exceções, os kujà/curandores que compõem a rede de xamãs que atendem os Kaingang na bacia do Rio Uruguai se conhecem, pelo menos têm informações sobre seus colegas, algumas vezes aprimoram o seu dom a partir $\mathrm{da}$ troca de ideias com alguém, mas também competem com um terceiro. 
Assim, por exemplo, Teresa Peskagar, que mora na Barra Seca, já ouviu falar da Carula. Teresa inclusive fez menção à dificuldade que os Kaingang da TI Votouro têm para visitar essa profissional na cidade de Nonoai, devido à ausência de uma linha de ônibus (Nonoai-Erechim) no turno da tarde.

De forma afetuosa, Teresa se reporta ainda a Sofia Kischer como a "manquinha", pois Sofia teve paralisia infantil quando criança e hoje tem uma perna maior que a outra, tendo com isto dificuldade para caminhar. Aliás, as duas são descendentes de pais poloneses que colonizaram a região do Alto Uruguai. Ela também conhece Darci Brandino, sabe que é um dos grandes conhecedores de ervas, um especialista na confecção de remédios para reumatismo. Em tempos idos, Teresa Peskagar tratou um dos filhos desse homem e sua esposa Iracema, que se tornou doente pelo uso e pela ingestão de veneno na lavoura durante a gravidez por sua mãe.

Podemos dizer que, também é comum kujà/curandores trabalharem juntos em uma determinada situação de doença. Em Nonoai, durante muito tempo o falecido João Lopes e a Carula trocaram informações entre si. Nas palavras de Carula, "inclusive o seu João Lopes me deu muita força quando ele era mais novo, nos meus benzimentos; muita força, Deus que abençoe ele".

Carula também conhece Darci Brandino. Uma certa vez, quando uma filha desse homem foi enfeitiçada devido ao ciúme de uma mulher por seu marido, ele não titubeou em levá-la para uma consulta junto a Carula. Além disso, essa profissional tornou-se, a partir de 2005, a principal responsável pela formação de Darci enquanto um kujà/curandor. Atualmente, esse profissional é considerado pelos Kaingang como um dos mais poderosos kujà da TI Votouro.

Além das relações de parceria, troca de saberes, formação, $k u j a ̀$ curandores também fazem críticas aos colegas tomados como oponentes ou inimigos diretos. Mas, a partir da lógica do xamanismo kaingang, essa relação não tem necessariamente a mesma contrapartida. Quer dizer, não se trata de A ser rival de $\mathrm{B}$ e vice-versa. Na maioria dos casos, A é inimigo de B, B é oponente de C, C é contrário a D e D é hostil a B e C, por exemplo. Com alguma exceção que outra, a relação quase nunca é direta. 0 principio que sobressai é que todo kujà tem um rival em potencial.

Nesse caminho, o fato de um kujà/curandor não ter conseguido curar alguém diante de um feitiço sempre é lembrado pelo seu oponente direto. Os próprios pacientes kaingang, quando decidem consultar-se com outro kujà, terminam por responsabilizar esse profissional por não curá-lo, exacerbando 
ainda mais a autoestima dessa pessoa e acirrando sua rivalidade com relação a esse outrem.

A partir disso, foi desse modo que Teresa Peskagar falou-me sobre a visita de Darci Brandino e Iracema a sua casa, após eles terem se consultado com a kujà Madalena de Paula:

Ela foi lá naquela de Paula, ela não fez efeito na menina, daí ela veio ali, com duas vezes a menina ficou boa. 0 piazinho [menor] deles, aquele doente, eles também foram por tudo, não conseguiram curar, eles vieram aqui, a criança até hoje esta boa, nunca mais ficou doente.

0 grau de rivalidade pode ser percebido a partir de um comentário fortuito, quase despercebido, uma crítica velada até uma crítica explícita, um enfrentamento direto ao seu rival. Segundo Jorge Kagnãg Garcia, os antigos kujà também "brigavam; discutiam valendo; vi discussão dele sobre doença, remédio, meu sistema era por aí; a comunidade sempre acompanhava; eram igual ao médico".

A partir de meus dados de campo, os "guerreiros" mais ásperos são Luisa Marcolina, Madalena de Paula, Joane Xavier Rigon e Jorge Kagnãg Garcia. Esses muitas vezes deixaram transparentes as suas divergências com relação ao tratamento dado a um/a opositor/a direto/a.

Por exemplo, Luisa Marcolina não tem meias palavras para criticar 0 trabalho de Madalena de Paula. Ela menciona que Madalena somente sabe fazer remédio "não fervido", quer dizer "socado no pilão". Em suas palavras:

Tem que falar para a Madalena queimar para você, tem que cobrar isso da Madalena. Ela não conheceu os antigos, as histórias dos antigos; ela pratica somente essa cura nova. Eu repasso as informações para ela; tem que dar remédio do mato às crianças.

Com a intenção de compreender tal rivalidade, perguntei à própria Madalena de Paula se Luisa seria uma boa kujà, ponto onde aparece a oportunidade para uma crítica velada ou explícita. Para minha surpresa, Madalena disse 0 seguinte: 
É curandeira também, curandeira também. Tá cega também, coitada. Dorva [professor bilíngüe Dorvalino Refej Cardoso] disse que tá ruim da gente fazer as coisas com ela, porque ela esta bem velhinha, uma parte cega também, tava me falando esses dias. A gente já tá pra esse fim também. Ela tá fortinha, enxergar, coitada não enxerga nada. Ela sempre foi curandeira boa também, sempre foi.

Ou seja, os ataques de Luisa Marcolina não têm a mesma ressonância ou contrapartida em Madalena de Paula. Porém, Madalena não economiza palavras para atacar Joane Xavier Rigon.

Então esse Joane ali, esse que ta ali, ele cansou de me mandar porque diz que ele não vai atrás, ele só benze. Mas eu não, eu benzo e tudo e vou atrás dos espíritos das pessoas porque a minha guia é três. Eles são em três; tenho que pedir pra eles ir atrás daquela pessoa pra ver como é que tá, se ela está pra lá, lá o que é o lugar dos espíritos [nũgmẽ]; daí tenho que pedir pra eles irem juntos, então quando a gente vai pro outro lado porque é mesma coisa que a gente ir pro outro lado, daí tenho que acender a vela; ao menos uma vela tem que pedir pras aquelas pessoas que vem.

A diferença apontada pela kujà Madalena a respeito do trabalho dela $\mathrm{e}$ de Joane é o poder que ela possui de penetrar no nügme (mundo dos mortos) e arrancar desse lugar o kuprĩg (espírito) de um Kaingang que se encontra aprisionado por algum vẽnb-kuprĩg-kòrèg de um parente falecido que lá reside. Esse poder ela não reconhece na prática do seu oponente.

Esses tempos, esse Joane não pode curar uma criança. Ele disse pra essa mulher, leva essa criança pra outra velhinha lá. Outro dia de manhã cedo chegaram ali. 'O Joane disse assim pra nós'. Ele não trabalha, ele só benze, ele não trabalha com espírito. Mas nós não dormimos mais com essa criança. 'Me compra uma vela e me manda antes da noite'. Daí me mandaram, não é que a criança estava lá onde que os espíritos tavam mesmo. Tava lá no meio deles, disque; dando de comer à criancinha. Mas, então, se não vai atrás a criança morre; que se os parentes do espírito já estão levando, como é que vai se salvar, não pode se salvar. Vai indo que até que morre. 
Domingos Catabilio também manifestou desconforto em relação ao trabalho de Joane Xavier Rigon, pois ele não lhe curou em certa oportunidade, fato que levou Domingos a buscar por conta própria e risco o caminho do xamanismo. Em suas palavras: "Esse curandor aqui de Fachinal [Faxinalzinho], o que tinha ele me pelou tudo, levava rancho de sacada pra ele, dinheiro, talvez era pior, nunca melhorava”.

Agora na casa de Joane Xavier Rigon escutei censuras desse homem ao trabalho de João Lopes, falecido curandor que trabalhou em parceria com Carula, que até aquele momento era uma unanimidade na lista de nomes dos kujà/curandor que se responsabilizam pela saúde kaingang. Joane comentou que conhecia João Lopes por notícia, não pessoalmente, mas que uma de suas clientes havia se queixado a ele quanto ao preço do remédio que ele cobrava.

Ela foi pra ser atendida, ele benzeu ela; saiu um remédio pra ela. Deu uma garrafa de remédio pra ela por vinte e cinco mil réis. 'Quando termina tu venha de novo, pois pode ser que mude o remédio'. 0 remédio azedou. 'Eu sofro dos pulmões; tomei a metade e começou a fazer mal; me fez mal'. Pego ela e levo pro médico; ela tem calor nos pulmões; rareia o cigarro; vai esses comprimidos pro pulmão. Ele lá ele benze, mas não tem a consulta certa pra fazer o tratamento certo pra curar a pessoa.

Por sua vez, além de Madalena de Paula, Luisa Marcolina também dirigiu comentários repreensivos ao capelão Braulino Pereira Beline, o filho da falecida kujà Matilde da Silva: "aquele lá não sabe nada, vai à igreja e fica olhando os outros; quem rezava já morreram quase todos".

Mas existe também alguém bastante atento à Luisa Marcolina. Trata-se de Jorge Kagnãg Garcia ${ }^{8}$, que desde jovem acompanha o trabalho dessa kujà no Setor Bananeiras, na TI Nonoai. Em suas palavras, "ela era novona ainda, era forte, caminhava por toda parte, hoje até cega ela está". Quando eu lhe indaguei se acreditava no trabalho de Luisa, ele me disse de modo enfático:

Jorge: Nunca acreditei; achava o trabalho dela muito diferente dos antigos.

\footnotetext{
${ }^{8}$ Jorge e Luisa são dois kujà de metade kamẽ. A rivalidade entre kujà de mesma metade ou não precisará avançar nas próximas pesquisas etnológicas.
} 
Autor: Diferente?

Ela trabalhava com o Negrinho do Pastoreio, aquilo é só pro mal, no meu entendimento. A Marcolina, aquela trabalha com espírito que não é legal, eu nunca acreditei nela. Em festa dela eu nunca fui, e ela nunca me convidou mesmo. Eu não gosto do trabalho dela.

Em uma visita à casa de Carula, exibi as fotos dos kujà/curandeiros que atendem os Kaingang do Votouro. Aliás, a sequência de imagens selecionadas por mim tornou-se uma oportunidade para um kujà conhecer a fisionomia do outro. Durante essa oportunidade, Carula observou a caderneta onde Sofia anotava os nomes das pessoas que estavam em tratamento.

Mas Carula direcionou os comentários mais duros a Joane Xavier Rigon. Essa curandeira prestou atenção nos santos que fazem parte do altarzinho desse profissional ("ali tá o santo dele"), na sua casa, no seu fogão, na lenha na peça e, particularmente, na sua imagem, que até então, segundo a mesma, nunca havia visto: "cabelo comprido; nunca vi gente que trabalha de cabelo comprido; nunca vi. Os índios estão me dizendo que ele está muito fraco; pra trabalho ele está muito fraquinho".

As falas aqui apresentadas, as críticas de um kujà/curandor a outro, dizem respeito à relação de alteridade estabelecida por essas pessoas. Enfim, essas alianças e combates nos ajudarão a compreender, no tópico a seguir, a atmosfera que se projetou em torno da cura de Gãr Fej a partir do trabalho de um conjunto de profissionais ligados ao xamanismo desses Kaingang.

\section{A CURA DE $\boldsymbol{G} \tilde{A} R \boldsymbol{F E J}$}

No tópico acima, "As doenças que atormentam os Kaingang", falei do feitiço enviado à casa de Gãr Fej para atingi-la e matá-la. Agora, depois de haver apresentado algumas relações de alianças e belicosidade dos kujà/curandor, retomo as seguintes questões: quem teria enviado o malfeito a Gãr Fej? Por qual razão? Quais kujà/curandor a curaram?

Quando Gãr Fej retornou do Hospital de Caridade, as chances de cura dessa doença invisível pela medicina ocidental estavam esgotadas - mais do que isso, a suspeita de que se tratava de um feitiço enviado por alguém havia aumentado à medida que foi piorando a saúde dessa mulher. 
Tendo em vista a gravidade dessa doença invisível, pais, irmãos e filhos decidiram consultar com mais de um responsável pela mediação do bem-estar dos Kaingang. A própria Gãr Fej disse-me que um "malfeito tem que ser em dois."

Como a feitiçaria constitui uma atividade belicosa que pressupõe o trabalho de profissionais preparados para localizar a causa da mesma e anulá-la, os seus familiares foram à casa de Kafy, Vẽnh Vĩ, Fé Mág e Fág Nĩno - quatro "guerreiros da doença" (CRÉPEAU, 1988) que fazem parte do complexo xamânico dos Kaingang da TI Votouro - para solicitar a cura de Gãr Fej.

Devido à gravidade dessa situação, três desses quatro xamãs contatados dirigiram-se à casa dos pais de Gãr Fej, onde ela se encontrava acamada. Somente após a mudança desse quadro clínico, ela passou a frequentar semanalmente 0 altarzinho da casa de Vẽnh Vĩ para participar da novena, conforme a prescrição terapêutica definida por esse mediador.

A kujà/curandora Fé Mág foi a primeira pessoa a ser consultada pelos pais de Gãa Fej. Conforme seus comentários:

Mulher gritando na cama, meu Deus do céu. A mãe dela veio aqui, chorando, tava gritando, dor de cabeça. 0 pai dela estava chorando, então eu botei um pouco de água fria, ela tava babando, peguei, puxei a perna dela. Eu mandei a mãe dela tirar a blusa dela, benzi, disse: 'é malfeito!'. Com remédio fui puxando devagarzinho na goela um osso de galinha, ele saiu bem limpinho, depois coloquei água fria ali, outro saiu de novo. Mas, ora, saiu um espinho de ouriço da boca dela. Botei na garrafa, umas horas ela melhorou um pouco.

Isto é, a opinião de que se tratava de um feitiço partiu de um consenso entre a pessoa que realizou o diagnóstico terapêutico e os familiares de Gãr Fej. Por outro lado, a entrada consecutiva de quatro mediadores para curar Gãr Fej também gerou um mal-estar para esses especialistas, devido à lógica ascensional do poder xamânico e à ideologia da guerra dessa instituição social.

Assim, quando Fé Mág soube que eles haviam consultado com Fág Nĩno, que tal profissional também estava participando do processo de cura de Gãr Fej, ela decidiu não atender mais essa paciente. Em suas palavras:

\footnotetext{
${ }^{9}$ Os nomes de Gãr Fej e dos kujà/curandor (Kafy, Vẽnh Vĩ, Fé Mág e Fág Nĩno) que trabalham para a cura do feitiço enviado a essa mulher são fictícios.
} 
Se a gente quer bem a gente tem que ver um só. Eu soube que você foi na outra curandeira, ela veio buscar remédio, eu não vou benzer ninguém mais, não vou fazer remédio. Vai lá! [risos] A gente tem que passar pra outro, meu remédio não ta valendo nada. Vai pra outro curandor; vai estorvar o outro. Daí ela foi, eu meio chateei ela também.

No fim dessa situação, Fág Nĩno, Vẽnh Vĩ e Kafy curaram juntos Gãr Fej, desse modo selando uma aliança xamânica temporária. No caso da curandora $K a f y$, a vítima não foi pessoalmente, mas o seu filho levou uma muda de roupa dela. Quanto à participação de Fág Nĩno, ela confirmou que Kajẽr, desesperado, havia ido a sua casa para solicitar que ela curasse sua esposa. No complexo xamânico dos Kaingang, cabe à pessoa doente ou a um parente envolvido também a responsabilidade por se deslocar à casa de um mediador para solicitar 0 tratamento.

Tu vê, essa mulher que eu tô dizendo que tava quase morrendo, vivia pro hospital, não tinha nada de volta, nada de volta, no fim ela mandou o marido dela vir aqui, daí eu fui lá, a mulher tava quase sem prosa, tava quase sem prosa. Ela disse pra mim: 'faz um favor de fazer um remédio pra mim, me benze'. Daí eu vim de volta com a condução pra nós pegar 0 remédio ali, cozinhei, mas estava quase morta a mulher, meu Deus.

Enquanto responsável pela farmacopéia dos Kaingang, Fág Nĩno cozinhou bastante remédio do mato para curar a sua paciente Gãr Fej. Dessa vez, foram necessários três dias para o restabelecimento da voz dessa mulher e dez dias para a mesma retomar a vontade de se alimentar. Ainda segundo Fág Nino:

Mas tava feia ela, no outro dia ainda cozinhando remédio ainda, ela vá tomar, vá tomar, quando foi três dias a coitada já tava conversando bem com nós, mas ela não comia, ela ficou quase dez dias sem engolir nada, só água, só água, só água, só água; não, a mulher tava morta, a mulher tava morta, mas demo a volta nela. Meu Deus do céu.

Também na parte do tratamento de Vẽnh $V \tilde{\imath}$, o trabalho estendeu-se por várias semanas após Gãr Fej ter se recuperado da crise mais aguda desse feitiço, 
quando então ficava em casa, deitada na cama, somente olhando às pessoas à sua volta. No dia que nos encontramos na casa de Vẽnh Vĩ , era a quarta-feira, a quinta consecutiva que Gãr Fej se dirigia a esse domínio para participar de uma novena realizada junto ao altarzinho dessa casa ${ }^{10}$.

Além da realização dessa novena durante nove semanas consecutivas, a outra etapa do itinerário terapêutico de Gãr Fej consistiu na mudança de casa dessa enferma porque esse espaço ficou contaminado após ela ter sido atingida pelo feitiço. Sendo assim, Gãr Fej decidiu morar temporariamente na residência de seus pais, a poucos metros de sua casa, até que, na época, seu marido retornasse de Santa Catarina, onde ele se encontrava vendendo artesanato.

A causa desse malfeito que atingiu o corpo de Gãr Fej e exigiu a busca de quatro mediadores que acompanham os Kaingang do Votouro, gira em torno da disputa entre mulheres pelos homens dessa comunidade. Nas palavras de Fág Nino:

Essa pessoa que fez pra ela é uma mulher à toa aí, ela fez pra modo do marido dela, pra matar ela, pra ela ficar com ele. Em vez demo a volta na mulher, me contento também porque a coitada também, se contento também porque voltou da porta do cemitério.

Embora este aspecto seja muitas vezes negado, no caso de uma feitiçaria, o kujà buscará retornar o malfeito enviado por um/a inimigo/a potencial do seu paciente ou por outro/a profissional. Isto é, "se a gente pode tocar pra aquela pessoa, a gente toca também, tem que tocar pra ver se não dói também no corpo, pra ver se não dói."

Quando conversei com Gãr Fej, na casa de seus pais, agora sobre a contribuição do trabalho de Vẽnh Vĩ contra esse feitiço, ela fez um comentário

\footnotetext{
${ }^{10}$ Durante a novena, Vẽnh Vĩ pediu a benção para os santos católicos e a proteção do corpo de Gãr Fej. Nessa reza especial, os santos comentados foram Pai, Espírito Santo, Nossa Senhora Virgem Maria, Cristo Jesus, Nossa Senhora Aparecida, Nossa Senhora da Saúde, Nossa Senhora da Dor, Nossa Senhora do Calmo, Nossa Senhora da Paz, Nosso Santo Papa, Nossa Senhora de Fátima, Nossa Senhora do Rosário, Nossa Senhora Coração de Maria, Nossa Senhora da Luz, São José, Nossa Senhora do Socorro, São Joaquim, São Paulo e São João Maria. Para finalizar essa quinta novena, ele rezou três Pai Nosso, duas Ave Maria, uma Glória ao Pai, dois Creio em Deus Pai e uma Salve Rainha.
} 
que encaixou outra peça importante desse quebra-cabeça do contexto que desencadeou tal situação: a relação de seu cônjuge com outra mulher.

\begin{abstract}
Assim, às vezes, tem homem que traem a mulher, ele fica batendo na mulher em casa, saem para fazer a arte deles, depois chegam batendo em casa, a gente não sabe o que, que é, a gente vai lá, [Vẽnh Vĩ] diz bem, bem certinho, que ele tem uma outra pessoa que, de certo ele gosta mais e agarra raiva da família, até dos filhos, às vezes. A gente vai lá [Vẽnh Vĩ] conta bem certinho: 'eu vou contar pra você, só que não vai ficar brabo teu marido tem outra companheira, daí ele já não se dá bem com você'. Ele já diz pra você, 'eu vou benzer o nome dele, daí ele vai endireitar'.
\end{abstract}

Pelo que se pode reparar, a disputa pelo marido de Gãr Fej por uma segunda mulher foi a razão da origem dessa doença invisível. Essa ação desencadeou uma reação por parte do conjunto de kujà/curandor chamado para atender essa situação de feitiço. Como no caso dos Toba argentinos (WRIGHT, 1992), um "guerreiro da doença" kaingang pode tanto curar como danificar uma pessoa de acordo com sua necessidade.

Nesse caso, a doença invisível produzida por feitiço originou-se em uma técnica manipulada por uma mulher ou por um(a) profissional para a conquista do marido de outrem a sua cliente. Esse fato desencadeou um dano físico irreparável: inicialmente, o feitiço enviado à esposa preterida; e, a seguir, à própria concorrente, devido ao envio de um contrafeitiço.

Trata-se de uma situação de enorme risco de vida tanto por parte da pessoa que é enfeitiçada quando por parte de quem ataca. Isso se deve às alianças que as mesmas estabelecem com algum conjunto de "guerreiros da doença" vinculado à sua rede de parentesco e relações - geralmente pessoas mais velhas - justamente para se protegerem da violência física que um feitiço ocasiona a sua vítima.

Como um interlocutor destas múltiplas características que dizem respeito às doenças invisíveis, o kujà/curandor age sempre procurando o benefício das pessoas que solicitam os seus serviços, na busca do reequilíbrio social através da resolução do conflito, mesmo que para isto tenha que, em alguma circunstância, devolver o feitiço ao mandante para vingar o paciente vitimado.

Apesar de um $k u j a ̀$ curandor poder identificar por intermédio de seu jagrẽ a origem de um feitiço, ou seja, quem enviou essa doença invisível, esse 
profissional não revela o nome de tal pessoa. Eles não fazem isso também para se protegerem do sentimento de vingança por parte da vítima. Nas palavras de Fág Nino:

Não tem que contar, elas [espírito auxiliar] dizem pra mim que não é pra contar porque a pessoa se incomoda bastante, a pessoa doente se incomoda bastante; pra não incomodar muito a gente não conta.

Em nossas conversas, Fé Mág, Fág Nĩno e Vẽnh Vĩ se esquivavam ao falar sobre a autora do infortúnio que se atravessara na vida de Gãr Fej. Mas, nesse caso, a própria vítima intuiu pelas falas do kujà/curandor que a enviou o malfeito, evidenciando ter certa consciência da situação em que esteve enredada. Ou seja, para Gãr Fej havia sido o espírito de uma jovem recém-morta, falecida poucos meses antes, a responsável por sua mazela.

Você soube aquela menina que [...] ela tava grávida, uma menina de quatorze anos tava grávida, perdeu a criança, morreu a mãe e a criança. Daí, de certo eu gostava tanto, gostava tanto dessa guria, quando ela faleceu, daí de certo eu estava fraca demais. [Vẽnh Vĩ] disse: 'ela estava fraca e pensa muito nessa guria, o espírito dela invocou'. Daí que eu não comia nada e andava sempre com a barriga cheia. Daí disseram pra mim, que eu não comia nada, mas diz que ela tava dando de comer pra mim. E a gente não sentia.

Em resumo, como no caso das sociedades amazônicas Achuar e Yagua, a feitiçaria e a sua contrapartida, o xamanismo, para os Kaingang também são atividades belicosas (CRÉPEAU, 1988; CHAUMEIL, 2000).

\section{OS KUJÀ SÃO DIFERENTES?}

Retomo a pergunta lançada já no título desse artigo: os kujà são diferentes? Durante meu trabalho de campo escutei os Kaingang dizerem que um kujà/curandor não é igual a outro devido à influência das diferentes espécies de jagrẽ na personalidade e no trabalho desse profissional.

Inclusive, um kujà é mais poderoso que seu colega devido a tais espécies que habitam na floresta e, em especial, por causa da qualidade de poder que estes 
jagrẽ cedem a esse profissional da saúde. Como fala Jorge Kagnãg Garcia, "o kujà não é de um jeito só”.

Talvez, por conta disso, seja possível compreender porque os kujà/curandores são pessoas de personalidade forte e idiossincráticas. Aliás, vimos acima que outra característica do xamanismo kaingang é que tais profissionais elegem alguns colegas para estabelecerem alianças e outros para, indiretamente, combaterem. Isso porque, os meus dados apontam que, por exemplo, Luisa Marcolino ataca Madalena de Paula, Madalena é indiscreta em relação a Joane Xavier Rigon, Joane molesta João Lopes e Jorge Kagnãg Garcia rivaliza com Luisa.

Por essas razões concluo que sim, os kujá/curandores são diferentes na medida em que eles têm espíritos auxiliares, formações e personalidades que ressaltam elevada autoestima.

Mas os princípios que regem seus trabalhos e suas decisões também são atravessados por uma lógica que atravessa 0 xamanismo (por exemplo, na relação do sistema kujà com o sistema caboclo, no trabalho em conjunto do jaguar com 0 Santo Antônio) e a mitologia kaingang (na origem dos heróis kamẽ e kanhru), onde a unidade junta a diversidade, o conjunto engloba o elemento (DUMONT, 1992; ROSA, 2014).

Nesse caso, a floresta/deus ultrapassa a diversidade de espíritos dos seres, o sistema kujà retém o sistema caboclo e 0 xamanismo kaingang orienta as idiossincrasias dos kujà/curandor, mas sempre deixando a possibilidade para uma reviravolta.

\section{REFERÊNCIAS}

ALMEIDA, Ledson Kurtz de. Análise Antropológica das Igrejas Cristãs entre os Kaingang baseada na Etnografia, na Cosmologia e Dualismo. 2004. 278 fls. Dissertação (Doutorado em Antropologia Social) - Universidade Federal de Santa Catarina, Florianópolis, 2004.

BORBA, Telémaco Morocines. Actualidade Indigena. Curitiba: Imprensa Paranaense, 1908.

CHAUMEIL, Jean-Pierre. Voir Savoir Pouvoir: le Chamanisme chez les Yagua de l’Amazonie péruvienne. Genéve: Georg Editeur, 2000. 
CRÉPEAU, Robert R. Les substances du chamanisme perspectives sudamerindiennes. Antbropologie et Societés, Quebec, v. 31, n. 3. 2007.

CRÉPEAU, Robert R. Le chamane croit-il vraiment à sés manipulations et à leurs fondements intellectuels? Recherches Amérindiennes au Québec, Montreal, v. 27, n. 3-4. 1997.

CRÉPEAU, Robert $\mathrm{R}$. Mythe et rituel chez les indiens kaingang du bresil meridional. Religiologiques, Paris, n. 10. Paris. 1994

CRÉPEAU, Robert R. Le Chamane Achuar - thérapeutique et sócio-politique. Recherches Amérindiennes au Québec, Montreal, v. 18, n. 2-3. 1988.

DUMONT, Louis. Homo bierarchicus: o sistema de castas e suas implicações. São Paulo: EDUSP, 1992.

HAVERROTH, Moacir. Kaingang - Um Estudo Etnobotânico: o uso $e$ a classificação das plantas na Área Indígena Xapecó. 1997. 182 fls. Dissertação (Mestrado em Antropologia Social) - Universidade Federal de Santa Catarina, Florianópolis, 1997.

LANGDON, Jean Matteson; BAER, Gerhard (Orgs.). Portals of Power: Shamanism in South America. Albuquerque: University of New Mexico Press, 1992.

OLIVEIRA, Maria Conceição de. Dinâmica do Sistema Cultural de Saúde Kaingang - Aldeia Xapecó, Santa Catarina. In: MOTA, Lúcio Tadeu.; NOELLI, Francisco S.; TOMMASINO, Kimiye (Org.). Urí e Wãxí: estudos interdisciplinares dos Kaingang. Londrina: EDUEL, 2000.

OLIVEIRA, Maria Conceição de. Os Curadores Kaingáng e a recriação de suas práticas: estudo de caso na Aldeia Xapecó (Oeste de S.C.). 1996. Dissertação (Mestrado em Antropologia Social) - Universidade Federal de Santa Catarina, Florianópolis, 1996.

PERRIN, Michel. Théories et Pratiques Médicales des Indiens Goajiro. Actes $d u$ XLIIe Congrès International des Américanistes, Paris, v. 6. 1978.

ROSA, Rogério Reus Gonçalves da. 0 Xamanismo Kaingang: a relação dos kujà com os espíritos animais/vegetais da floresta e os santos do panteão do catolicismo popular. In: FLECK, E. C. D. Religiões e religiosidades no Rio Grande do Sul: manifestações da religiosidade indígena. São Paulo: ANPUH, 2014.

ROSA, Rogério Reus Gonçalves da. Mitologia e Xamanismo nas relações sociais dos Inuit e dos Kaingang. Espaço Ameríndio, Porto Alegre, v. 5, n. 3. 2011. 
ROSA, Rogério Reus Gonçalves da. Os Kujà São Diferentes: um estudo etnológico do complexo xamânico dos Kaingang da Terra Indígena Votouro. 2005. 416 fls. Tese (Doutorado em Antropologia Social) - Universidade Federal do Rio Grande do Sul, Porto Alegre. 2005.

WRIGHT, Pablo G. Dream, Shamanism and Power among the Toba of Formosa Province. In: LANGDON J. M.; BAER, G. (Org.). Portals of power: shamanism in south America. Albuquerque: University of New Mexico Press, 1992. 